\title{
Amorphous determination in calcium sulfoaluminate materials by external and internal methods
}

Marta García-Maté

PhD student, Departamento de Química Inorgánica, Universidad de Málaga, Malaga, Spain

Isabel Santacruz

Ramón y Cajal Fellow, Departamento de Química Inorgánica, Universidad de Málaga, Malaga, Spain

\section{Ana Cuesta}

PhD student, Departamento de Química Inorgánica, Universidad de Málaga, Malaga, Spain

\section{Laura León-Reina}

X-ray diffraction laboratory supervisor, Servicios Centrales de Apoyo a la Investigación, Universidad de Málaga, Malaga, Spain

\section{Miguel A. G. Aranda}

Professor, Departamento de Química Inorgánica, Cristalografía y

Mineralogía, Universidad de Málaga, Málaga, Spain; CELLS-Alba synchrotron, Cerdanyola, Barcelona, Spain

\author{
Isabelle Baco \\ Research and development technician, Lafarge Centre de Recherche, \\ Saint-Quentin-Fallavier, France \\ Vincent Morin \\ Project leader - Aether research, Lafarge Centre de Recherche, Saint- \\ Quentin-Fallavier, France \\ Günther Walenta \\ Project manager $\mathrm{CO}_{2}$, Lafarge Centre de Recherche, Saint-Quentin- \\ Fallavier, France \\ Ellis Gartner \\ Scientific director, Chemistry, Lafarge Centre de Recherche, Saint- \\ Quentin-Fallavier, France \\ Ángeles G. De la Torre \\ Lecturer, Departamento de Química Inorgánica, Universidad de Málaga, \\ Malaga, Spain
}

External standard methodology has been successfully applied to quantify the known amounts of amorphous component that are increasingly added to cement-related materials. The consistency and accuracy of the methodology were demonstrated by the $R^{2}$ values of the least-square fits determined against weighed amorphous amounts, which were close to 1.0 in all the series. This method requires common laboratory X-ray powder diffractometers (knowing the equipment constant) and avoids the dilution/alteration of the sample. However, the obtained values may be biased due to poor particle statistics. On the other hand, internal standard analysis in transmission geometry is suitable to determine the absolute amorphous and crystalline non-quantified contents that are less biased owing to enhanced particle averaging statistics. This method is, however, experimentally tedious due to the addition of the internal standard and the sample loading in the X-ray diffraction sample holders which represent inherent drawbacks to follow amorphous evolutions.

\section{Introduction}

Cements based on clinkers rich in the calcium sulfoaluminate phase, also called ye'elimite $\left(\mathrm{C}_{4} \mathrm{~A}_{3} \mathrm{~s}\right)$, typically in combination with belite and calcium-aluminoferrites, are produced in significant quantities for specialty applications, and also have the potential for even more widespread application in the future as low-energy cements with an exceptionally low carbon footprint (Aranda and De la Torre, 2013; Gartner, 2004; Pérez-Bravo et al., 2013). Quantitative analysis of such clinkers, and also of their hydration products, is an essential part of the research process needed to better understand how they hydrate and thus how their performance can be modified for any given application. The only method readily available for quantitative phase analysis of these materials in the laboratory is quantitative $\mathrm{X}$ ray diffractometry (XRD) coupled with Rietveld analysis. However, the absolute accuracy of such methods is very dependent on the 'degree of crystallinity' of the solids present, as 'X-ray amorphous' phases cannot be directly measured. Thus, some way of accurately estimating the total mass of material that is not detected directly (and which hence is considered to be 'X-ray amorphous') is needed. The research described in this paper was aimed at improving the accuracy of these methods, especially as applied to cement rich in calcium sulfoaluminate (De la Torre et al., 2001; Jansen et al., 2011a; O'Connor and Raven, 1988; Walenta et al., 2002).

\section{Materials and methods}

\section{Materials}

Two different sulfobelite clinkers produced by Lafarge (France), codes K171p3 and LHY-04097-53, and two supplementary cementitious materials (SCM), a fly ash (FA) and a natural limestone (LS), were studied. Glass powder, obtained by grinding very thin optical glass plate by hand in an agate mortar for $30 \mathrm{~min}$, was also used in this work. Table 1 gives the elemental analysis for the raw materials determined by X-ray fluorescence (XRF) measured in a Magic X spectrometer (Panalytical, Almelo, The Netherlands) using the calibration curve of silica-alumina 


\begin{tabular}{|c|c|c|c|c|c|}
\hline & K171p3: wt\% & LHY-04097-53: wt\% & FA@wt\% & Limestone: wt\% & Glass: wt $\%$ \\
\hline Calcium oxide $(\mathrm{CaO})$ & $52 \cdot 62$ & $49 \cdot 74$ & $10 \cdot 29$ & $54 \cdot 20$ & $5 \cdot 80$ \\
\hline Silicon dioxide $\left(\mathrm{SiO}_{2}\right)$ & $15 \cdot 83$ & $14 \cdot 01$ & $56 \cdot 65$ & $1 \cdot 17$ & $72 \cdot 50$ \\
\hline Aluminium oxide $\left(\mathrm{Al}_{2} \mathrm{O}_{3}\right)$ & $16 \cdot 64$ & $19 \cdot 32$ & $23 \cdot 29$ & 0.52 & $1 \cdot 50$ \\
\hline Iron (III) oxide $\left(\mathrm{Fe}_{2} \mathrm{O}_{3}\right)$ & $6 \cdot 87$ & $6 \cdot 95$ & $3 \cdot 49$ & $0 \cdot 27$ & 0.00 \\
\hline Sulfur trioxide $\left(\mathrm{SO}_{3}\right)$ & $4 \cdot 74$ & $4 \cdot 82$ & 0.23 & 0.04 & $0 \cdot 30$ \\
\hline Sodium oxide $\left(\mathrm{Na}_{2} \mathrm{O}\right)$ & $0 \cdot 11$ & 0.08 & $2 \cdot 66$ & 0.07 & $13 \cdot 30$ \\
\hline Potassium oxide $\left(\mathrm{K}_{2} \mathrm{O}\right)$ & $0 \cdot 72$ & $0 \cdot 81$ & 0.63 & $0 \cdot 10$ & $1 \cdot 60$ \\
\hline Magnesium oxide (MgO) & $0 \cdot 51$ & $1 \cdot 52$ & $1 \cdot 13$ & $0 \cdot 59$ & $3 \cdot 80$ \\
\hline Strontium oxide $(\mathrm{SrO})$ & - & $0 \cdot 16$ & 0.08 & 0.03 & - \\
\hline Titanium oxide $\left(\mathrm{TiO}_{2}\right)$ & 0.33 & 0.97 & 0.62 & 0.03 & $0 \cdot 40$ \\
\hline Manganese (III) oxide & - & 0.06 & 0.06 & 0.00 & \\
\hline Zinc oxide (ZnO) & 0.04 & - & - & 0.00 & $0 \cdot 80$ \\
\hline Phoshporous pentoxide $\left(\mathrm{P}_{2} \mathrm{O}_{5}\right)$ & 0.06 & 0.06 & - & 0.00 & - \\
\hline Zirconium dioxide $\left(\mathrm{ZrO}_{2}\right)$ & 0.00 & 0.00 & 0.09 & 0.00 & \\
\hline Loss on ignition (Lol) & $1 \cdot 53$ & $1 \cdot 51$ & 0.69 & $42 \cdot 98$ & - \\
\hline Total & $100 \cdot 00$ & $100 \cdot 00$ & $100 \cdot 00$ & $100 \cdot 00$ & $100 \cdot 00$ \\
\hline
\end{tabular}

Table 1. Elemental composition, expressed as weight percentage of oxides, for the samples as determined by $\mathrm{X}$-ray fluorescence (XRF)

materials in the case of clinkers and in a Magix Pro spectrometer (Panalytical, Almelo, The Netherlands) in the case of SCMs and glass.

\section{Mixtures with known amount of amorphous phase}

A known (weighed) amount of glass (G) was mixed with the materials detailed above. Four sets of samples were prepared: $(a)$ K171p3 with $0 \cdot 00,5 \cdot 50,10 \cdot 08,15.04$ and $20.21 \mathrm{wt} \%$ of glass (labelled as K-xG); (b) LHY-04097-53 with $0 \cdot 00,5 \cdot 20,10 \cdot 00$, $15 \cdot 10$ and $20 \cdot 10 \mathrm{wt} \%$ of glass (labelled as LHY-xG); (c) limestone with $0.00,5.06,10.09,15.02$ and $20.02 \mathrm{wt} \%$ of glass (labelled as LS-xG); and $(d)$ K171p3 with $0 \cdot 00,5 \cdot 00,10 \cdot 00$, 15.00 and $20.00 \mathrm{wt} \%$ of glass prepared at Lafarge Centre de Recherche (France) (labelled as K-xG-LCR). Mixtures $(a)-(c)$ were prepared by co-grinding the materials by hand in an agate mortar for $15 \mathrm{~min}$, and mixtures $(d)$ were prepared in the same way but co-grinding for $30 \mathrm{~min}$.

\section{Mixtures with internal standards}

NIST SRM-676a ( $\alpha$-aluminium oxide) was used as internal standard. The weighed percentages of internal standard are given in Table 2. All mixtures were homogenised by hand for $15 \mathrm{~min}$ in an agate mortar.

\section{Analytical techniques}

\section{Laboratory X-ray powder diffraction}

All the samples were studied by laboratory X-ray powder diffraction (LXRPD) to identify, characterise and quantify the crystalline phases.

\begin{tabular}{lcc}
\hline & $\begin{array}{c}\text { International standard: } \\
\text { wt\% }\end{array}$ & Absorption factor \\
\hline Limestone & $30 \cdot 36$ & $2 \cdot 9$ \\
Fly ash & $30 \cdot 07$ & $2 \cdot 5$ \\
& & $2 \cdot 9$ \\
K171p3 & $30 \cdot 25$ & $2 \cdot 7$ \\
& & $2 \cdot 4$ \\
& & $2 \cdot 8$
\end{tabular}

Table 2. Weighed percentage of internal standard, aluminium oxide, added to each sample. Absorption factors for mixtures loaded in flat sample holders for transmission X-ray powder diffraction measurement are also given. Each sample was loaded and measured twice

Patterns for all the samples (with and without added glass) were recorded in Bragg-Brentano reflection geometry $(\theta / 2 \theta)$ on an X'Pert Pro multipurpose diffractometer (MPD) (Panalytical B.V.) using strictly monochromatic $\mathrm{CuK} \alpha_{1}$ radiation $(\lambda=$ $0 \cdot 154059 \mathrm{~nm})(\mathrm{Ge}(111)$ primary monochromator). The X-ray tube worked at $45 \mathrm{kV}$ and $40 \mathrm{~mA}$. The optics configuration was a fixed divergence slit $\left(1 / 2^{\circ}\right)$, a fixed incident antiscatter slit $\left(1^{\circ}\right)$, a fixed diffracted antiscatter slit $\left(1 / 2^{\circ}\right)$ and $X^{\prime}$ Celerator RTMS (real-time multiple strip) detector, working in scanning mode with maximum active length. Data were collected from $5^{\circ}$ to $70^{\circ}(2 \theta)$ for $\sim 2 \mathrm{~h}$. The samples were rotated at $16 \mathrm{r} / \mathrm{min}$ during data collection in order to enhance particle statistics. In addition, the 
external standard approach (which is explained below) requires the recording of a standard pattern collected in identical diffractometer configuration/conditions and as close in time as possible to the sample measurements. The methodology detailed in Jansen et al. (2011a) was performed by using a polished polycrystalline quartz rock as secondary standard, placed on the diffractometer in the very same orientation for each measurement without sample spinning. The suitability of this quartz rock was tested against NIST SRM-676a ( $\alpha$-aluminium oxide) (Cline et al., 2011).

In addition the samples with internal standard were recorded in flat-sample transmission geometry on an Empyrean diffractometer (Panalytical B.V.) equipped with a $\theta / \theta$ goniometer, $\mathrm{CuK} \alpha_{1,2}$ radiation $(\lambda=0 \cdot 1542 \mathrm{~nm})$ and a focusing mirror. This last PreFIX optical component is capable of converting the divergent beam into convergent radiation focused on the goniometer circle and of removing $\operatorname{CuK} \beta$ radiation. The Empyrean diffractometer was equipped with fixed incident and diffracted beam anti-scatter slits of $\frac{10}{4}$ and $5 \mathrm{~mm}$, respectively. The detector was Pixcel 3D RTMS, which comprises more than 65000 pixels, each $55 \times 55 \mu \mathrm{m}$ in size and having its own circuitry. The powder samples (mixed with $\alpha$-aluminium oxide) were placed by duplicate in the flat sample holders between two Kapton films. The absorption coefficient was measured for all samples by comparing the direct beam with and without sample. The amount of sample (and thickness) was tuned to obtain absorption coefficients close to $2 \cdot 7$, see Table 2 . Data were collected from $5^{\circ}$ to $70^{\circ}(2 \theta)$ for $\sim 3 \mathrm{~h}$ and rotated at $16 \mathrm{r} / \mathrm{min}$.

\section{LXRPD data analysis}

All the patterns were analysed by the Rietveld method with X'Pert Highscore Plus software from Panalytical B.V., version $3 \cdot 0 \mathrm{e}$. The refined overall parameters were: cell parameters, zeroshift error, peak shape parameter and phase fractions. Background functions were accounted for by selecting 'use available' tool of the software. Peak shapes were fitted by using the pseudoVoigt function (Thompson et al., 1987) with the asymmetry correction included (Finger et al., 1994) by refining U, V and W (Gaussian contribution) and peak shape 1 (Lorentzian contribution) when appropriated. Crystal structure descriptions for all the phases were those published elsewhere (Álvarez-Pinazo et al., 2012) except for ye'elimite, for which a revised orthorhombic crystal structure was used (Cuesta et al., 2013).

\section{Amorphous and crystalline non-quantified (ACn) fraction determination}

The simplest method of deriving the phase content from the Rietveld refined scale factor uses the approximation that the sample is only composed of crystalline phases with known structures (the 'normalisation to full crystalline content' method). Using this approach, the internal standard methodology (De la Torre et al., 2001) was employed by adding an $\alpha$-aluminium oxide standard as detailed above. If the original sample contains an amorphous phase or any 'non-quantifiable' crystalline phase, the standard will be overestimated in the Rietveld quantitative phase analysis. From the (slight) overestimation of the standard, the 'amorphous' content of the investigated sample can be determined.

The external standard methodology, also known as the G-factor approach, allows the determination of the absolute weight fractions by previously obtaining the diffractometer constant, and knowing the mass attenuation coefficients of the samples (Jansen et al., 2011a, 2011b; O'Connor and Raven, 1988).

These approaches quantify not only amorphous/sub-cooled phases but also misfit problems of the analysed crystalline phases and any non-included crystalline phases. Hereafter, this derived value will be called 'amorphous and crystalline non-quantified', ACn (Aranda et al., 2012).

\section{Results and discussion}

\section{Accuracy using external standard methodology}

To check the accuracy of the external standard method, four sets of samples with known amounts of glass, plus the corresponding glass-free samples, were analysed. Figure 1 shows the ACn values derived using the $\mathrm{G}$-factor method for all the samples in each series (solid symbols) plotted as a function of added glass content. Open symbols represent the average ACn values obtained by the same methodology for the samples without added glass. The least-square fit parameters are included in the graphs as insets. All $R^{2}$ values are close to $1 \cdot 0$, showing the consistency of the methodology. This demonstrates that the increase of $\mathrm{ACn}$ content in a crystalline mixture can be successfully quantified by this external-standard methodology, which is of even greater utility in the study of hydration of cement pastes. Clinker K171p3 was mixed with glass by two different operators using different mixing methodologies, but the results, in Figures 1(a) and 1(b), show very similar ACn values. They are all within $2 \mathrm{wt} \%$, over the range of glass contents studied. This confirms that the mixture preparation methodology only had a minor effect on ACn determination by the external standard procedure. The 'accuracy' of the results was checked by comparing the direct measurement values (obtained from samples without any glass addition) and the value calculated from the intercept of the best-fit line. The direct $\mathrm{ACn}$ values (average value of two analyses) were 17.8, 24.1 and 17.9 wt $\%$ for K171p3, LHY-04097-53 and LS, respectively. The intercepts for the same samples derived from the calibration curves were: $14.2,23.8$ and $13.6 \mathrm{wt} \%$, respectively. Therefore, the direct values are slightly overestimated for K171p3 and LS, Figures 1(a) and 1(d), whereas the value for LHY-04097-53 clinker matches very well, Figure 1(c). Both K171p3 and LHY-0409753 are sulfobelite clinkers, but they have different chemical compositions (Table 1), K171p3 being poorer in aluminium oxide content. Figure 2 shows a selected range of the Rietveld plots for both clinkers to highlight the differences in the degrees of crystallinity of the phases. K171p3 clinker phases give sharper diffraction peaks than those of clinker LHY-04097-53. This observation suggests that the ACn value for K171p3 should 


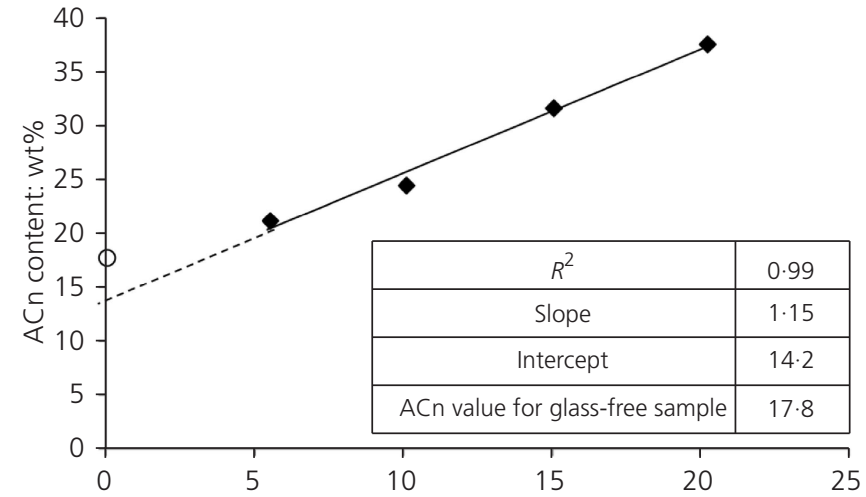

(a)

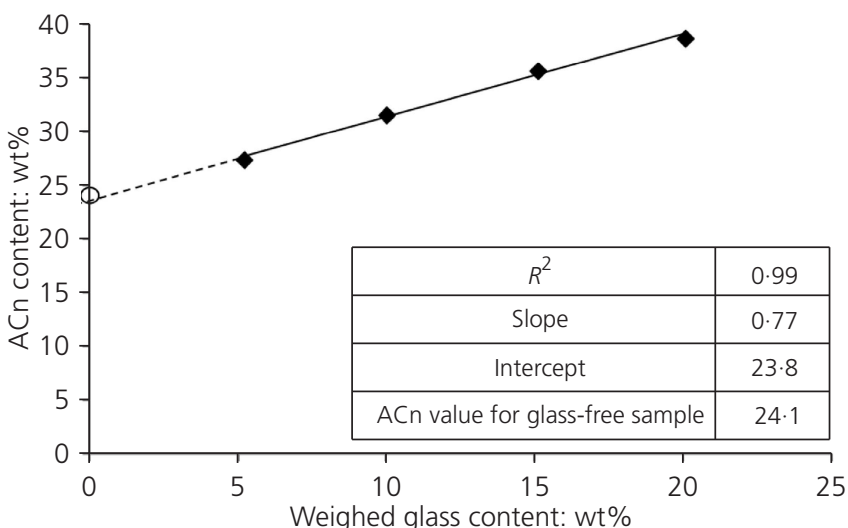

(c)

Figure 1. ACn contents, in weight percentage, as a function of the amount of added glass obtained by G-factor method for (a) K-xG, (b) K-xG-LCR, (c) LHY-xG and (d) LS-xG. Insets include

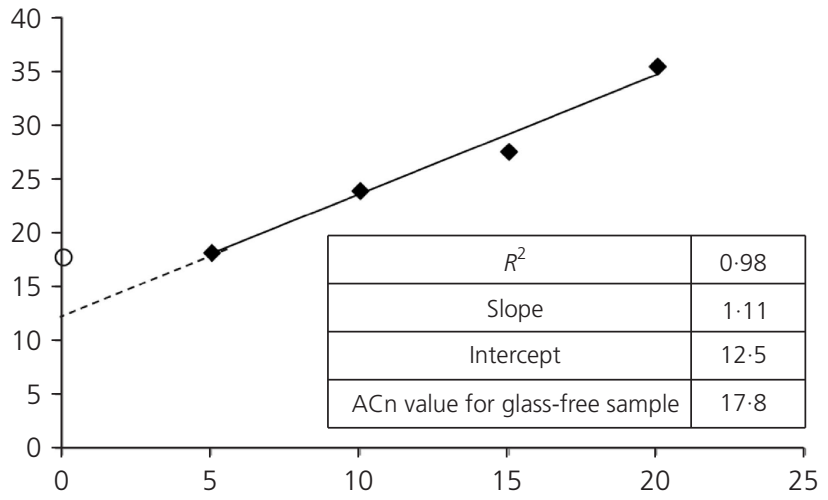

(b)

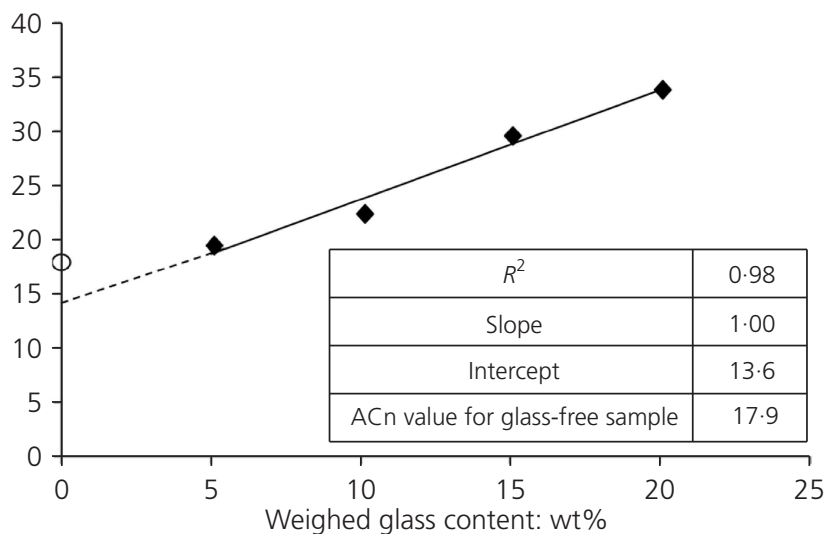

(d)

least-square fit data. Open symbols indicate the derived ACn content in the samples without any added glass be smaller than that of LHY-04097-53, as corroborated by the experimental results. Furthermore, sharp diffraction peaks are attributable to large particle sizes, and this may have a negative effect in the particle statistics in powder diffraction. This may be the explanation of the slight overestimation in the ACn content of the clinker (De la Torre and Aranda, 2003; Westphal et al., 2002). This phenomenon was also observed for the LS-G samples. Limestone is a well-crystallised natural rock comprising mainly calcite, and consequently its $\mathrm{ACn}$ should be low. However, LS powder patterns (obtained in reflection geometry) show preferred orientation, which was corrected by using the March-Dollase algorithm (Dollase, 1986). Table 3 includes the refined preferred orientation (PO) ratio values for all the samples, corrected along the [lll $\left.\begin{array}{ll}1 & 0\end{array}\right]$ axis. Again, this fact may justify the slight overestimation of the ACn content of the LS sample. The ACn content of LS was measured in triplicate, Table 3, and it can be observed that the pattern with the lowest PO ratio value, meaning the highest degree of orientation, yielded the largest overestimation of the ACn value, confirming the negative effect of poor particle distribution statistics in the G-factor methodology.

\section{External and internal standard methodologies: comparison}

To check if relatively poor particle statistics is playing a role in the systematic overestimation of ACn by the external standard methodology, a new set of experiments was designed. The internal standard methodology was also used to derive ACn contents in those samples for which the intercept and the experimental $\mathrm{ACn}$ values obtained through the external standard methodology did not match: that is, samples LS and K171p3. It is noted that working in transmission with a focused X-ray beam enhances particle statistics because a larger sample volume is tested. Tables 3 and 4 report the results from both methodologies and the numbers stand for the number of repetitions of the measurements (and the analyses). By 'repetition' means the uploading and reloading of the samples/mixtures in the sample holders to collect new LXRPD patterns.

Table 3 shows the full Rietveld mineralogical analysis, including ACn, for LS. Transmission geometry gives two beneficial effects: (a) lower preferred orientation; and (b) larger analysed sample volume. This combination resulted in a smaller average $\mathrm{ACn}$ 


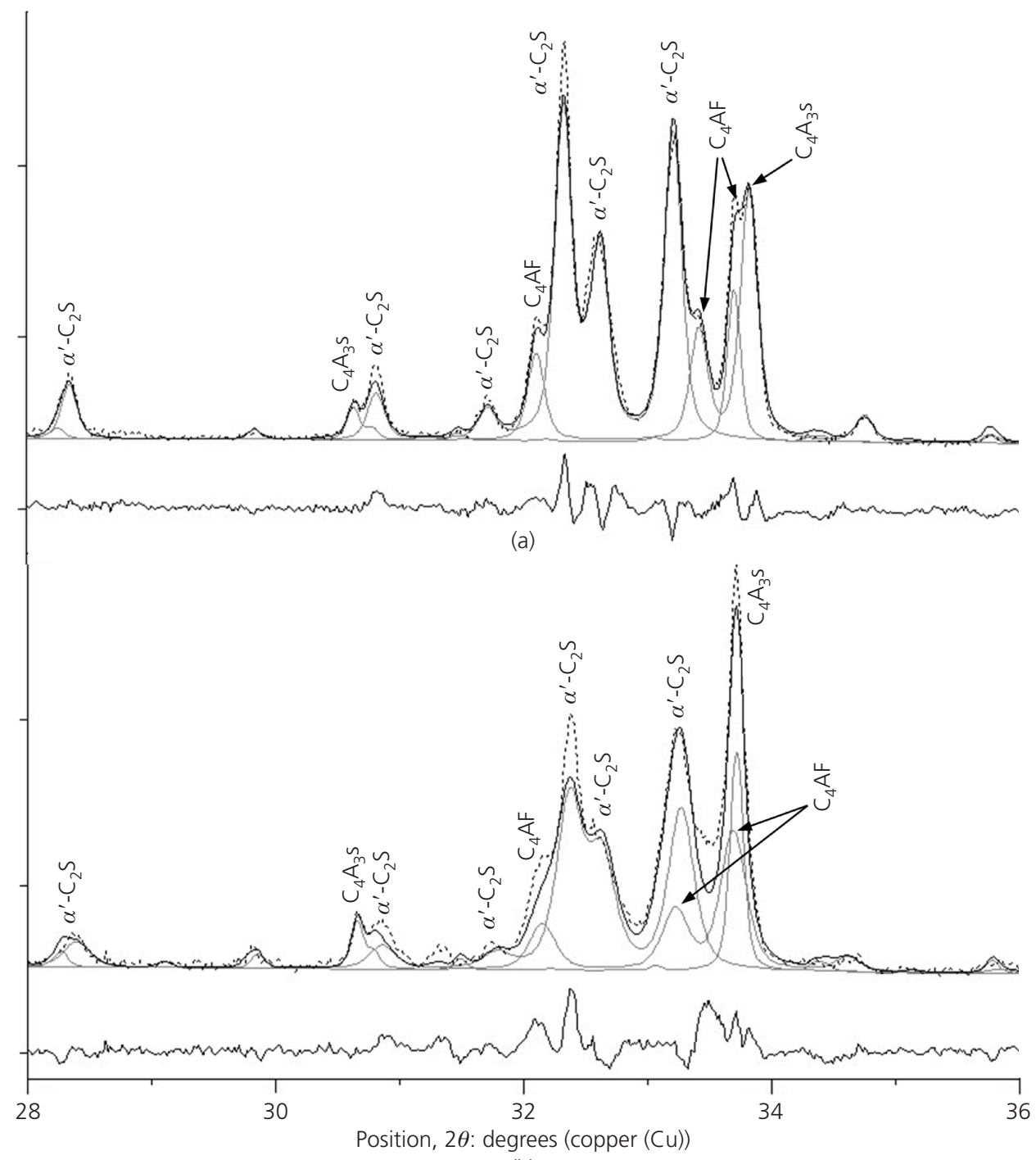

(b)

Figure 2. Selected angular range of the Rietveld plots for (a) K171p3 and (b) LHY-04097-53 clinkers. Dotted lines are the experimental pattern, black solid lines stand for the calculated pattern, solid line at the bottom and for the difference curve and grey solid lines represent the individual phase patterns. Main peaks attributable to a given phase have been labelled

\begin{tabular}{|c|c|c|c|c|c|}
\hline & $\begin{array}{c}\text { External } \\
\text { standard } 1\end{array}$ & $\begin{array}{c}\text { External } \\
\text { standard } 2\end{array}$ & $\begin{array}{c}\text { External } \\
\text { standard } 3\end{array}$ & $\begin{array}{c}\text { Internal } \\
\text { standard } 1\end{array}$ & $\begin{array}{c}\text { Internal } \\
\text { standard } 2\end{array}$ \\
\hline Calcium carbonate $\left(\mathrm{CaCO}_{3}\right)$ & $83 \cdot 8$ & $78 \cdot 4$ & $81 \cdot 0$ & $90 \cdot 3$ & $88 \cdot 1$ \\
\hline Quartz & $0 \cdot 4$ & 0.8 & 0.9 & $1 \cdot 0$ & $2 \cdot 0$ \\
\hline Dolomite & $0 \cdot 3$ & $0 \cdot 4$ & $0 \cdot 3$ & - & - \\
\hline$A C n$ & $15 \cdot 5$ & $20 \cdot 4$ & $17 \cdot 8$ & $8 \cdot 7$ & $9 \cdot 9$ \\
\hline $\mathrm{PO}$ calcium carbonate $\left(\mathrm{CaCO}_{3}\right)$ & 0.89 & 0.83 & 0.86 & 0.96 & 0.95 \\
\hline \multicolumn{6}{|c|}{$\begin{array}{l}\text { Table 3. Full mineralogical analysis, wt\%, including ACn } \\
\text { contents, derived by external and internal standard } \\
\text { methodologies for sample LS. Refined preferred orientation (PO) } \\
\text { ratio for calcium carbonate along }\left[\begin{array}{lll}1 & 0 & 4\end{array}\right] \text { axis is also reported }\end{array}$} \\
\hline
\end{tabular}


External standard $1 \quad$ External standard $2 \quad$ Internal standard 1 Internal standard 2

\begin{tabular}{|c|c|c|c|c|}
\hline$\alpha^{\prime}$-dicalcium silicate $\left(C_{2} S\right)$ & $48 \cdot 2$ & $46 \cdot 8$ & $51 \cdot 2$ & $47 \cdot 9$ \\
\hline Ye'elimite $\left(\mathrm{C}_{4} \mathrm{~A}_{3} \mathrm{~S}\right)$ & $20 \cdot 6$ & $19 \cdot 5$ & $21 \cdot 9$ & $20 \cdot 8$ \\
\hline Tricalcium aluminate $\left(\mathrm{C}_{4} \mathrm{AF}\right)$ & $14 \cdot 7$ & $14 \cdot 5$ & $13 \cdot 3$ & $12 \cdot 6$ \\
\hline $\mathrm{ACn}$ & $16 \cdot 5$ & $19 \cdot 2$ & $13 \cdot 6$ & $18 \cdot 7$ \\
\hline
\end{tabular}

Table 4. Full mineralogical analysis, wt\%, including ACn

contents, derived by external and internal standard

methodologies for sample K171p3

\begin{tabular}{|c|c|c|c|c|c|}
\hline & $\begin{array}{c}\text { External } \\
\text { standard } 1\end{array}$ & $\begin{array}{c}\text { External } \\
\text { standard } 2\end{array}$ & $\begin{array}{c}\text { External } \\
\text { standard } 3\end{array}$ & $\begin{array}{c}\text { Internal } \\
\text { standard } 1\end{array}$ & $\begin{array}{c}\text { Internal } \\
\text { standard } 2\end{array}$ \\
\hline Mullite & $6 \cdot 0$ & $5 \cdot 7$ & $5 \cdot 1$ & $7 \cdot 5$ & $6 \cdot 9$ \\
\hline Quartz & $3 \cdot 7$ & $4 \cdot 4$ & $3 \cdot 4$ & $4 \cdot 4$ & $4 \cdot 3$ \\
\hline Magnesium oxide (MgO) & $0 \cdot 1$ & $0 \cdot 0$ & $0 \cdot 0$ & $0 \cdot 3$ & $0 \cdot 3$ \\
\hline Calcium oxide (CaO) & 0.5 & 0.4 & 0.4 & - & - \\
\hline$A C n$ & $89 \cdot 7$ & $89 \cdot 5$ & $91 \cdot 1$ & $87 \cdot 8$ & $88 \cdot 5$ \\
\hline
\end{tabular}

value, $9 \mathrm{wt} \%$, compared with the intercept of the calibration curve, $13.6 \mathrm{wt} \%$, and the average value from G-factor methodology, $18 \mathrm{wt} \%$. These overestimations seem to be consistent and could be corrected.

Table 4 shows the full Rietveld mineralogical analysis, including $\mathrm{ACn}$, for $\mathrm{K} 171 \mathrm{p} 3$. The $\mathrm{ACn}$ average value determined from the internal standard methodology was $16 \mathrm{wt} \%$. This value compares very well with the intercept of the calibration curve, $14 \cdot 2 \mathrm{wt} \%$, and the average value from G-factor methodology, $18 \mathrm{wt} \%$.

Finally, Table 5 gives the ACn content for the FA sample. The $\mathrm{ACn}$ average value from the internal standard methodology, $88 \mathrm{wt} \%$, agrees well with that from the external standard methodology, $90 \mathrm{wt} \%$. These were the highest values measured in this study and these are typical numbers for fly ash. Moreover, ACn deviations obtained by using the internal standard methodology are intrinsically minimised when these values are very high (Westphal et al., 2009).

\section{Conclusions}

It has been shown that the increase of the amorphous and nonquantified crystalline solid contents in a mixed powder can be followed by an external standard methodology, by preparing mixtures of clinkers and SCMs with known amounts of glass (amorphous component). This method has the inherent benefit of using common experimental requirements of LXRPD (knowing the diffractometer constant) and, moreover, the sample is not altered/diluted by introducing any internal standard.

The internal standard methodology applied to transmission LXRPD is useful to corroborate and scale the values obtained by the external standard methodology (reflection geometry). Internal standard analysis in transmission leads to the derivation of $\mathrm{ACn}$ contents that are less biased because the particle averaging statistics are enhanced. However, this approach is not very suitable to follow ACn evolution in a process because it is experimentally tedious due to the addition of the internal standard and the sample loading in the XRD sample holders.

\section{Acknowledgements}

The work in Malaga has been supported by Spanish Mineco through MAT2010-16213, which is co-funded by FEDER and by Junta de Andalucía through P11-FQM-07517 research grants, and was also supported by the central research of Lafarge close to Lyon. I. Santacruz would like to acknowledge, with thanks, a Ramón y Cajal fellowship, RYC-2008-03523.

\section{REFERENCES}

Álvarez-Pinazo G, Cuesta A, García-Maté M et al. (2012) Rietveld quantitative phase analysis of Yeelimite-containing cements. Cement and Concrete Research 42(7): 960-971.

Aranda MAG and De la Torre AG (2013) Sulfoaluminate cement. In Eco-efficient concrete (Pacheco-Torgal F, Jalali S, 
Labrincha J and John VM (eds)). Woodhead Publishing Limited, Cambridge, UK, pp. 488-522.

Aranda MAG, De la Torre AG and León-Reina L (2012) Rietveld quantitative phase analysis of OPC clinkers, cements and hydration products. Reviews in Mineralogy and Geochemistry 74(1): 169-209.

Cline JP, Von Dreele RB, Winburn R et al. (2011) Addressing the amorphous content issue in quantitative phase analysis: the certification of NIST standard reference material 676a. Acta Crystallographica Section A 67(4): 357-367.

Cuesta A, De La Torre AG, Losilla ER et al. (2013) Structure, atomistic simulations, and phase transition of stoichiometric yeelimite. Chemistry of Materials 25(9): 1680-1687.

De la Torre AG and Aranda MAG (2003) Accuracy in Rietveld quantitative phase analysis of Portland cements. Journal of Applied Crystallography 36(5): 1169-1176.

De la Torre AG, Bruque S and Aranda MAG (2001) Rietveld quantitative amorphous content analysis. Journal of Applied Crystallography 34(2): 196-202.

Dollase WA (1986) Correction of intensities for preferred orientation in powder diffractometry: application of the March model. Journal of Applied Crystallography 19(4): 267-272.

Finger LW, Cox DE and Jephcoat AP (1994) A correction for powder diffraction peak asymmetry due to diaxial divergence. Journal of Applied Crystallography 27(6): 892-900.

Gartner E (2004) Industrially interesting approaches to 'low $\mathrm{CO}_{2}$ ' cements. Cement and Concrete Research 34(9): 1489-1498.
Jansen D, Goetz-Neunhoeffer F, Stabler CH et al. (2011a) A remastered external standard method applied to the quantification of early OPC hydration. Cement and Concrete Research 41(6): 602-608.

Jansen D, Stabler CH, Goetz-Neunhoeffer F et al. (2011b) Does ordinary Portland cement contain amorphous phase? A quantitative study using an external standard method. Powder Diffraction 26(1): 31-38.

O'Connor BH and Raven MD (1988) Application of the Rietveld refinement procedure in assaying powdered mixtures. Powder Diffraction 3(1): 2-6.

Pérez-Bravo R, Álvarez-Pinazo G, Compana JM et al. (2013) Alite sulfoaluminate clinker: Rietveld mineralogical and SEMEDX analysis. Advances in Cement Research 26(1): 10-20, http://dx.doi.org/10.1680/adcr.12.00044.

Thompson P, Cox DE and Hasting JB (1987) Rietveld refinement of Debye-Scherrer synchrotron X-ray data from $\mathrm{Al}_{2} \mathrm{O}_{3}$. Journal of Applied Crystallography 20(2): 79-83.

Walenta G, Füllmann T, Westphal T et al. (2002) Process and Apparatus for X-ray Diffraction Characterization of a Material with Amorphous Phase. Global Patent index EP1260812A1.

Westphal T, Füllmann T and Pöllmann H (2009) Rietveld quantification of amorphous portions with an internal standard-mathematical consequences of the experimental approach. Powder Diffraction 24(3): 239-243.

Westphal T, Walenta G, Giménez M et al. (2002) Characterisation of cementitious materials - part III. International Cement Review July: 47-51.

\section{WHAT DO YOU THINK?}

To discuss this paper, please submit up to 500 words to the editor at journals@ice.org.uk. Your contribution will be forwarded to the author(s) for a reply and, if considered appropriate by the editorial panel, will be published as a discussion in a future issue of the journal. 